\title{
Recommendations on the management of services for in vitro fertilisation from the WHO (regional office for Europe) 1990
}

\section{Assessment of infertility}

The term "infertility" is defined by WHO as failure to conceive after at least two years of unprotected intercourse. The prevalence of infertility is estimated to be roughly $10 \%$ in industrialised countries. Accurate estimates of the prevalence of infertility, ascertainment of the current availability of resources (medical and social), and a determination of how they are used by infertile women and men are the foundations of rational planning.

(1) Each country needs to determine the prevalence of primary and secondary infertility by gender and cause.

(2) Each country needs to assess the availability of medical and social options for infertile women and men.

(3) Each country needs to determine the proportion of the infertile population choosing the various social (adoption, fostering, voluntary childlessness) and medical options in vitro fertilisation, other medical treatments).

\section{Infertility services}

PREVENTION PROGRAMMES

Not enough is known about the causes of infertility or the effectiveness of infertility prevention programmes.

(4) There is a need for research on the preventable causes of infertility, including the role of environmental factors, workplace hazards, contraceptives, iatrogenic causes, sexually transmitted diseases, and emotional factors.

(5) The effectiveness of infertility prevention programmes needs careful evaluation.

\section{SOCIAL OPTIONS}

For many people a social option (voluntary childlessness, foster parenting, or adoption) may be the preferred solution to the problem of infertility.

(6) Each country needs to assess the social options available to infertile people, including counselling services, barriers to these options, and inequities in access to these options.

(7) Research is needed on the attitudes of the general public and of infertile women and men towards medical and social options. Such research should also assess the cultural and social meaning of infertility.

\section{MEDICAL OPTIONS - IVF AND RELATED}

TECHNOLOGIES

Because most countries have no mandatory licensing or reporting of clinical data on in vitro fertilisation, information on in vitro fertilisation services is difficult to obtain. There is great variation in service availability among countries. The rapid proliferation of in vitro fertilisation services in nearly all industrialised countries is driven by the interests of providers, industry, and other special interest groups, rather than by rational planning based on the needs of the population.

(8) Further proliferation of new in vitro fertilisation centres and expansion of services should not occur until countries have determined the need for infertility services, the priority for infertility services within all human services, and the priority for the various social and medical options for infertile women and men.

(9) The role of industry and commercial interests in in vitro fertilisation should be documented, including industry's role in funding research and its involvement in service pro- vision. This information should be available to the public.

(10) Governments should consider limiting the number of treatment cycles per woman.

(11) Governments should consider limiting the indications for in vitro fertilisation.

(12) According to the European Society of Human Reproduction and Embryology, the hazards of pregnancy increase and success rates drop for women over the age of 40 who undergo in vitro fertilisation. Governments should consider limiting eligibility for in vitro fertilisation to women of 40 and under.

\section{COUNSELLING AND SUPPORT}

For many individuals, the inability to conceive a child can be a major source of stress and unhappiness.

(13) Infertile individuals must have full information on the availability, risks, and effec tiveness of all social and medical options for the management of infertility. They must then, in turn, have free choice of the use of these options.

(14) Counselling should be available for infertile people. Interested individuals should be encouraged to seek help before contact with any type of infertility service. Infertile people may also be referred to mutual aid groups for support before, during, and after pursuing social or medical options.

(15) Counselling services and mutual aid groups must be independent of social and medical programmes for the management of infertility. Funding for these services should not come from clinics or industry.

\section{Technology assessment of IVF and related} technologies

EVALUATION OF THE NEW REPRODUCTIVE TECHNOLOGIES

In vitro fertilisation and related technologies have not been adequately evaluated. Published results of randomised clinicla trials to determine the true effectiveness of in vitro fertilisation are not yet available. Moreover, there has not been adequate research on the short term and long term risks associated with this treatment and others.

The best available epidemiological research indicates that in vitro fertilisation has limited effectiveness (fewer than 10 live birth per 100 treatment cycles), that pregnancy rates independent of treatment are high, and that cumulative effectiveness rates diminish after three to four cycles of treatment.

Serious risks are associated with in vitro fertilisation. The ovarian hyperstimulation syndrome occurs in $1-2 \%$ of women treated with ovulation inducing drugs. Multiple gestation occurs in about $25 \%$ of in vitro fertilisation pregnancies. The perinatal mortality rate for in vitro fertilisation babies is four times and the neonatal mortality rate twice that of the general population. The rate of very low birth weight among in vitro fertilisation babies is over 11 times higher than in the general population.

(16) There is a need for a standard definition of the effectiveness of in vitro fertilisation. The best definition for the purposes of evaluation and health planning is the number of live births per 100 treatment cycles.

(17) The effectiveness, short term safety, and cost of in vitro fertilisation must be scientifically determined through multicentre, randomised, clinical trials. As a treatment for a given cause of infertility in vitro fertilisation should be compared with other medical options and with no treatment.

(18) Case-control studies are needed to evaluate the short term and long term risks of ovulation induction and other in vitro fertilisation procedures.

(19) Until there is an adequate appraisal of the risks of ovulation induction and other in vitro fertilisation procedures countries should take steps to limit exposure of women and their offspring.

- More stringent guidelines on the indications for ovulation induction should be developed.

- Limits should be placed on the number of artificially stimulated cycles (both within and outside in vitro fertilisation) that women undergo.

- Ovulation stimulation protocols should be as simple as possible.

- For selected women, natural cycle in vitro fertilisation may be preferable.

- The practice of ovulation induction for the purposes of timing pregnancy or regulating the menstrual cycle should be discontinued.

- The practice of ovulation induction in normally ovulating women for the sole purpose of oocyte donation should be discontinued.

- Social options can be promoted.

- Prevention programmes can be implemented.

(20) All clinics should follow the guideline set out by the European Society of Human Reproduction and Embryology that limits the number of eggs or embryos transferred during an in vitro fertilisation treatment cycle to no more than three.

(21) Governments should set priorities for infertility research and make available adequate funding and other support.

costs

In vitro fertilisation is an expensive procedure. Its true costs have been underestimated by considering only the direct costs of one treatment cycle. In some countries the proportion of in vitro fertilisation costs paid by governments and private insurance has been hidden through separate billing for in vitro fertilisation procedures that cannot be distinguished from other gynaecological services, such as ultrasound, blood tests, and laparoscopy.

(22) Evaluation of the direct and indirect costs of in vitro fertilisation and related technologies is an essential part of rational planning. To calculate the costs of one birth from in vitro fertilisation one must include the costs of drugs, materials, and human resources for all treatment cycles, successful and failed, for all women enrolled in the programme. Pregnancies require more high risk obstetric care and babies more often require neonatal intensive care, so the costs of these services must be included as well. The costs of in vitro fertilisation then need to be compared with the costs of other forms of infertility care, both medical and social.

\section{Planning and resource allocation}

No country can afford to apply every health technology to every person it might benefit.

(23) Through surveys or other means the priority that the public at large assigns to 
infertility management vis à vis other social and health services is determined so that the appropriate proportion of all health and social resources can be allocated to infertility.

(24) Following this the public and policymakers decide on the priority to be given to each option, social and medical, for the management of infertility. This allows the appropriate proportion of the resources for infertility to be allocated to prevention, social options, conventional medical and surgical options, and in vitro fertilisation and related technologies.

\section{Quality assurance}

(25) As in vitro fertilisation and related technologies require knowledge and skill far beyond that of normal medical and gynaecological training, the certification of providers must be tied to training and demonstrated skill. Each in vitro fertilisation centre must have at least one such certified provider who assumes direct responsibility for certain crucial steps such as dispensing ovulation inducing drugs, evaluating potential new clients, evaluating clients wishing to repeat cycles, and training and supervising other clinic personnel.

(26) There should be mandatory reporting of all in vitro fertilisation cycles as a basis for quality assurance. Such population based registries would also provide sampling frames for research and data for ongoing assessment of the costs and benefits of in vitro fertilisation. Additionally, record linkage of in vitro fertilisation registries with birth defects and cancer registries may provide useful data for monitoring adverse effects of treatment.

(27) The monitoring and audit of in vitro fertilisation centres must be done by a team, the majority of members having no direct involvement in providing in vitro fertilisation. Sanctions for non-compliance with established standards should include closing the centre. The results of the monitoring and audit should be available to the public.

\section{Ethics}

Governments are under no obligation to ensure the availability of in vitro fertilisation to any person who might desire to have a child. Even if one acknowledges the individual's right to reproduce, this right cannot be extended automatically to those who do not have the capacity to reproduce.

(28) Ethical considerations in infertility need to focus first on the services provided (including equity, screening procedures, honesty of information, and the rights of women and men, not just on the egg, embryo, and fetus

(29) Service systems for infertility need mechanisms that provide for community participation in planning and monitoring these services, including their ethical aspects. The mechanisms must ensure that the nature of the services, including ethical issues, reflect the opinion of the entire community and are not dominated by service providers. Various models are available but generally include a local group of unbiased, well informed people, preferably having at least $50 \%$ women and a majority of lay people, whose selection is independent of the service providers. In addition, a similarly constituted group at national level is usually necessary. The mandates for these groups may be broader than infertility services, to include other types of health service. In some countries it is important for the mechanism to be given the full weight of the law, with regulatory powers given to the national group to monitor and enforce the law, with the assistance of the local groups. Whatever model is used, these groups must be accountable to the public and their deliberations should be available.
(30) Because it is against international law to discriminate against individuals on the basis of personal, racial, or social characteristics, countries should commit themselves, as an integral part of the provision of all infertility services, to a policy of non-discrimination:

- by enșuring that access to these services is not based on inappropriate use of irrelevant personal characteristics, such as race, sexual preference, or social, economic, or marital status;

- by providing appropriate mechanisms for the monitoring and review of access and screening decisions;

- by establishing an accessible and appropriate forum, with decision making and enforcement powers, for individuals seeking review of access decisions.

(31) To monitor the equity and ethical aspects of in vitro fertilisation services, centres should be required to report the demographic and social characteristics of clients. This information should be available to the public

(32) In every in vitro fertilisation centre activities that are primarily for the purpose of developing or contributing to general knowledge need to be labelled as research and clearly differentiated from activities that are primarily for the purpose of enhancing the well being of an individual client. There should be no incentives for clients to participate in research (for example, providing remuneration to clients who agree to participate in research or moving them to the top of the waiting list for treatment). Similarly, there should be no incentives for women seeking sterilisation to agree to undergo ovulation induction for the purpose of ovum donation. Clients who participate in research must be fully informed as to its nature, purpose, and conditions, and as to their rights as research subjects.

\section{NOTES}

- The world's first centre devoted entirely to research in multiple sclerosis is to be set up in Cambridge where a team of research workers will be led by Professor D A S Compston, professor of neurology at the University of Cambridge. The centre has been the brainchild of Dr Hamid Husain, a general practitioner in Rotherham, and the MS Research Centre Appeal was launched in 1990 , with a target of $£ 2 \mathrm{~m}$. This has now been achieved. The patrons of the appeal included Sir Douglas Black, Lord Pitt of Hampstead, and Lord Walton of Detchant, and the launch coincided with Sir Ranulph Fiennes's unassisted expedition to the North Pole, which supported the appeal.

\section{COMING EVENTS}

Institute of Medical Laboratory Sciences -Triennial conference, 5 to 12 September Liverpool. Details from Heather Tate IMLS, 12 Queen Anne Street, London W1M 0AU (tel 0716368192 ).

Public Health Research Unit, University of Glasgow, and WHO-Second international safe communities conference 7 to 9 September, Glasgow. Details from Meetings Makers, 50 Richmond Street, Glasgow G1 1XP (tel 041553 1930).

International Stroke Society-Second world congress, 8 to 23 September, Washington DC. Details from Ms D D Vernon, ISS convention manager, Wake Forest University Medical Center, Medical Center Boulevard, Winston-Salem, NC 27157-1074, USA.

The National Heart and Lung Institute Course "Introduction to clinical research," 15 and 16 September, London. Details from Christine Bull, Rostrum, Lewis House, Mildmay Road, Romford, Essex RM7 7DA (tel 0708735191 ).

Research and Development for Psychiatry - Conference "Homes not beds. Housing and residential care provision for people with mental health problems," 16 to 18 September, Reading. Details from RDP, 134-8 Borough High Street, London SE1 ILB (tel 0714038790 ).

British Society of Audiology-Clinical short papers' meeting, 23 September, London. Details from Mr Stewart Anderson, Cromwell Hospital, Cromwell Road, London SW 5 T U (tel 0713704233 ).

The Royal Society-Discussion meeting "Molecular chapresones," 23 and 24 September, London. Details from the executive secretary, The Royal Society, 6 Carlton House Terrace, London SW1Y 5AG (tel 0718395561 ).

The Society for Drug Research Symposium "Osteoporosis," 24 September, London. Details from Ms Barbara Cavilla, Society for Drug Research, 20 Queensberry
Place, Lond on S W $7.2 \mathrm{DZ}$ (tel Place, Lon
0715818333 ).
General Practice Research ClubAutumn meeting "Into Europe: in search of quality?" 26 September, Oxford. Detail from Dr John Wilmot, honorary secretary GPRC, Postgraduate Medicine, University of Warwick, Coventry CV4 7AL

International School of Pediatric Sciences - Course "Screening for neural tube defects, Down syndrome, cystic fibrosis and fragile X," I to 3 October, Sestr Levante, Genoa. Details from Ms Marcell Devoto, secretariat, S Grosso, Direzione Scientifica, Istituto G Gaslini, 1614

Addictions Forum - Conference "Alcohn and young people. Learning to cope, 7 October, London. Details from Hamis Macandrew, Addictions Forum, UnivEd Technologies Ltd, The University of Edinburgh EH8 0LL. (tel 0316503476 ).

American Association for the Advancement of Science-Meeting "Human genome '92," 14 to 17 October, Nicc Details from AAAS meetings office, $1333 \mathrm{H}$ Street, NW, Washington DC 20005 (te 2023266461 .

St George's Hospital Medical School Second international Jenner glyco immunology meeting, 1 and 2 November London. Details from Susan Henderson, Academic Rheumatology Unit, Division of Immunology, St George's Hospital Medical School, Cranmer Terrace, London SW17 ORE (tel 081672 9944, ext 55795 )

British Society of Audiology - Hearing aid audiology group study day, 2 November,
Middlesbrough. Details from Mr Graham Clarke, BSA, 80 Brighton Road, Reading, Berkshire RG6 IPS (tel 0734660622

British Association for Service to the Elderly-Details of study days from September to November are available from BASE Wales, 4th Floor, Transport House, 1 Cathedral Road, Cardiff CF1 9SD (tel 0222384545

\section{BMA MEETINGS}

Members proposing to attend meetings marked * are asked to notify in advance the honorary ecretary concerned.

Division meeting

Rotherham-At Rotherham Moat House, Moorgate Road, Rotherham, Wednesday 5 August, $730 \mathrm{pm}$, meeting to discus response to applications for trust status. *

Somerset-At the White House, Stoke St Mary, Taunton, Saturday 15 August, 730 pm, "Chairman's summer evening."

\section{Regional meetings}

Yorkshire Regional Office-Practice agreèments, Wednesday 30 September, Parkway Hotel, Otley Road, Leeds 16, $130 \mathrm{pm}$; and Wednesday 30 September, Postgraduate Centre, Hull Roval Infirmary, $645 \mathrm{pm}$. $£ 25$ for BMA members, $£ 30$ for non-members. Details from BMA non-members. Details from BMA
Yorkshire Regional Office, Sterling House, Northside Business Park, Shcepscar, Leeds LS7 2BB (tel 0532458745 ). 